\title{
DISCUSSION
}

\section{Is the quasi-steady state a real behaviour? A micromechanical perspective}

\author{
J. YANG and B. B. DAI (2011). Géotechnique 61, No. 2, 175-183, http://dx.doi.org/10.1680/geot.8.P.129
}

M. M. Rahman, University of South Australia, Mawson Lakes, Australia and S. R. Lo, University of New South Wales, Canberra, Australia

The authors (Yang \& Dai, 2011a) have revisited the issue of whether quasi-steady state (QSS) behaviour observed in laboratory testing is an aberration caused by experimental error, for example as argued by Zhang \& Garga (1997). The use of discrete-element method (DEM) analysis to avoid any experimental issues is novel. However, progress in laboratory testing techniques (such as successful use of free ends) largely removes that concern and it is generally believed that QSS behaviour is a real material behaviour (Vaid et al., 1989, 1999; Chu, 1999; Yoshimine, 1999; Lo et al., 2010). However, there is still the question of why QSS behaviour has not been clearly observed in the field. This can be explained in light of the so-called mechanism ' $\mathrm{C}$ ' as proposed by the National Research Council (NRC, 1985): liquefaction in the field is not simply element behaviour. It initiates within a 'zone' and then leads to void ratio and pore-water pressure redistribution within the soil mass. As this redistribution occurs continuously with shearing, some of the 'zones' of soils in the field can be represented by the condition of $\mathrm{d} \varepsilon_{\mathrm{v}} / \mathrm{d} \varepsilon_{\mathrm{q}}<0$. Bobei (2004) has conducted strain path (SP) testing to mimic such a condition. An undrained test, $\mathrm{B}_{1}$ is compared to SP tests in Fig. 10. $\mathrm{B}_{1}$ exhibited QSS. The equivalent test, SP was conducted at an undrained condition until QSS was just manifested as indicated by point $\mathrm{X}$ in Fig. 10. Then, three segments of SP testing with $\mathrm{d} \varepsilon_{\mathrm{v}} / \mathrm{d} \varepsilon_{\mathrm{q}}=-0 \cdot 05,-0 \cdot 10,-0.20$ were imposed. It can be observed that, upon the imposition of slightly dilative strain paths, the behaviour turned to strain softening, that is the QSS behaviour disappeared. The overall kinematics of liquefaction in the field as a boundary value problem is controlled by the 'weakest' behaviour. Thus, even at element level undrained behaviour only gives limited flow, that is QSS behaviour, which may be observed in the field as flow. This offers a plausible and theoretically sound explanation on why QSS has not been observed in many field conditions.

A fundamental question is whether QSS can be inferred by an effective stress constitutive model and imposition of an undrained condition. The effective stress constitutive

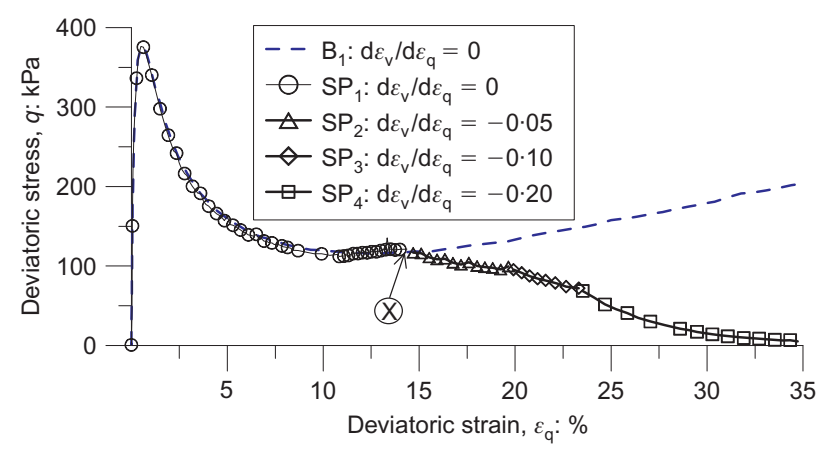

Fig. 10. Simulation of mechanism ' $C$ ' by SP testing; data modified after Lo et al. (2008) models (Cubrinovski \& Ishihara, 1998; Li \& Dafalias, 2000) can infer the occurrence of QSS as a result of the combined effect of stress-dilatancy behaviour (flow rule) and strain hardening in terms of effective stress. This suggests that QSS, in general, is not due to the occurrence of a special soil fabric. The authors' microscale study, which showed that the coordination number (i.e. number of contacts per particle) reduces to a minimum at QSS, may therefore not be a general feature of QSS, and may be caused by some of the assumptions made in the micromechanics analysis.

\section{Authors' reply}

The authors wish to thank Dr Rahman and Professor Lo for their interest in the paper. They raise the question why the QSS has not been observed in many field conditions. While it was out of the scope of the original paper, the authors welcome the opportunity to clarify this point. In the authors' view, whether or not the QSS can occur, either in the laboratory or in the field, depends on two primary conditions

(a) the granular soil should be sufficiently loose but not too loose

(b) the soil should be loaded under the constant volume condition or the undrained condition.

If none, or only one, of the two conditions is satisfied, the QSS will not occur.

The first condition stated above is to ensure, on one hand, that the void ratio at a given confining stress level is larger than the critical void ratio at the same stress level, thus avoiding a dilative response without any softening (i.e. state A in Fig. 11), and on the other hand, is to ensure that the void ratio is not too large, thus avoiding flow liquefaction without hardening (i.e. state $\mathrm{C}$ in Fig. 11). It is perhaps worth commenting that the position of the critical state line (CSL) in the void ratio-effective confining stress plane depends to some degree on the loading mode - that is, the CSL in triaxial compression may be somewhat different from that in triaxial extension. The important implication is that while the QSS may be observed in triaxial extension for a given soil state, it may not occur in triaxial compression for the same state.

With respect to the second condition - constant volume it can be well realised in the laboratory by controlling drainage of water, but cannot be rigorously satisfied in the field. When liquefaction initiates in a weak zone in soil masses, seepage and void change will usually take place (NRC, 1985) - this explains why the QSS cannot be observed in many field conditions. The discussers' test shown in Fig. 10 provides good evidence confirming that the QSS will not appear if the constant-volume condition is not satisfied.

A significant contribution of the paper is to reveal that the QSS marks a transition state at the microscale in that the number of inter-particle contacts declines before the state emerges, and after that it begins to increase with strain. This feature is not, as speculated by the discussers, caused by some specific assumptions introduced in the authors' modelling. Compared with the conventional macroscale constitu- 

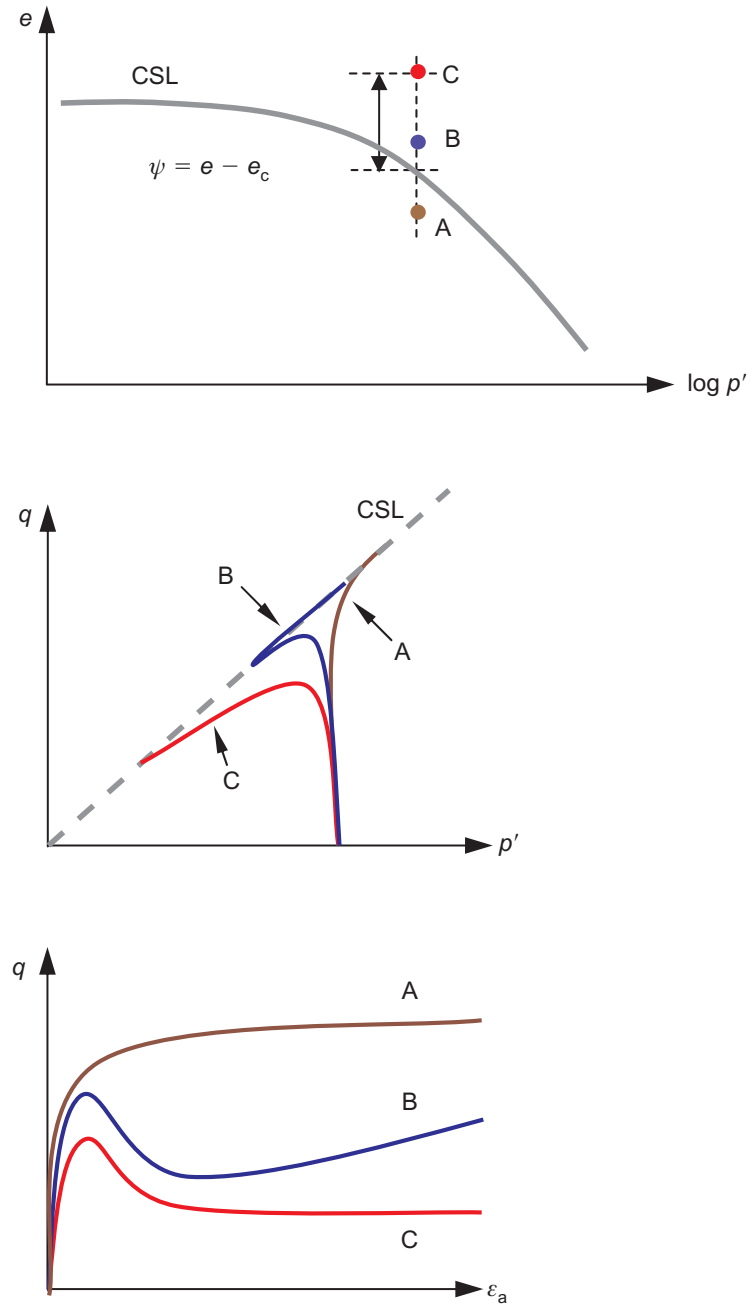

Fig. 11. Schematic illustration of typical granular soil behaviour under undrained triaxial compression

tive models that require assumptions of flow rule and hardening law - these are key to modelling the dilative/softening response and usually involve a large number of parameters - the grain-scale modelling technique used by the authors does not require such assumptions. It only adopts, as stated in the paper, a simple contact law assuming a linear relation between the contact force and the displacement and applying the Coulomb friction criterion at the contact. As shown in the paper under discussion and later in Yang \& Dai (2011b), many salient features of the macroscopic behaviour of granular soil, including the complicated effect of anisotropy, can be well captured using this simple contact model. In this respect, the grain-scale modelling has unique advantages.

Most recently, in testing a mixed soil comprising coarse, rounded sand particles and fine, spherical glass beads, Yang \& Wei (2011) have successfully obtained the first ever experimental evidence showing that the QSS represents a transition from a metastable to a stable microstructure, as shown here in Fig. 12. The soil specimen was consolidated to the confining pressure of $500 \mathrm{kPa}$ and the void ratio of 0.746 , and then subjected to triaxial compression under the undrained conditions. A marked feature of the results is that drastic fluctuations in the stress-strain response occurred in the initial stages of shearing and then vanished in the later portion of the test. The fluctuations are considered as the result of the interactions between spherical glass beads and rounded sand grains during shear, in the form of rapid losing and rebuilding of inter-particle contacts; and these fluctuations in stress would not cease until a stable microstructure

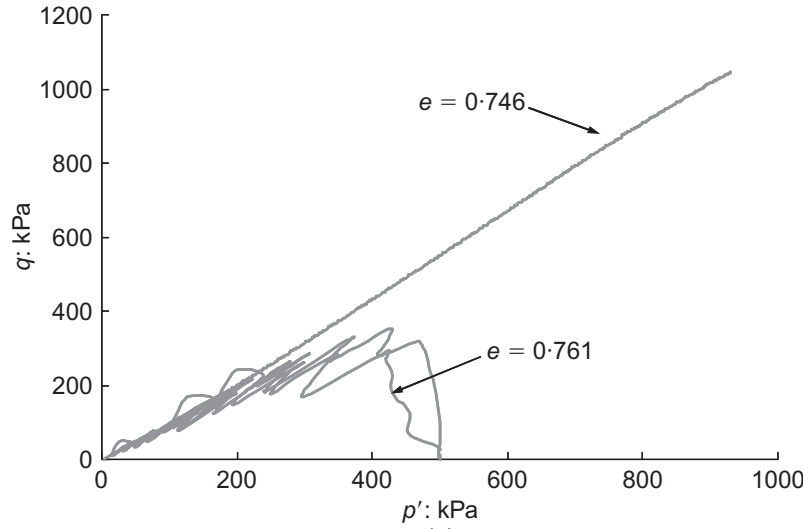

(a)

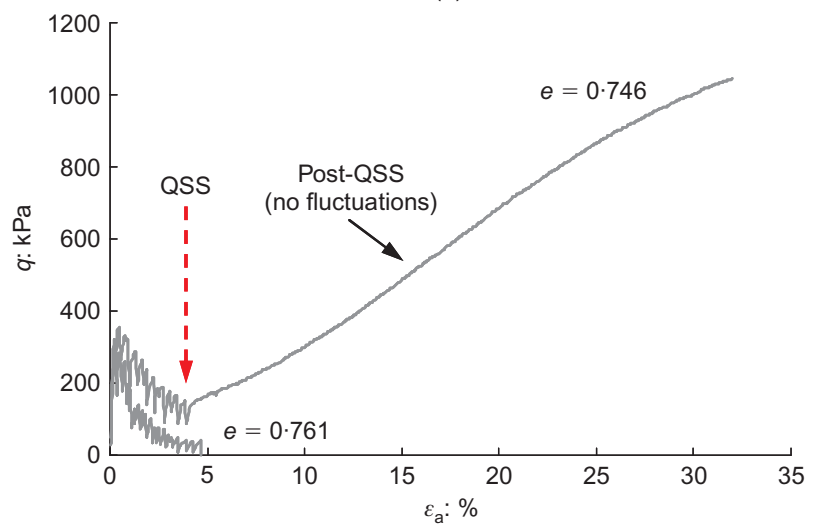

(b)

Fig. 12. Undrained shear behaviour of a mixed soil at different void ratios (Yang \& Wei, 2011): (a) stress path; (b) stress-strain curve

could be established. This hypothesis is confirmed by the observation that the fluctuations ceased when the specimen was sheared beyond the strain level of about $4 \%$. Note that at this strain level a local minimum strength was reached and beyond that a strain-hardening response occurred evidently this transition state is the QSS.

For the purpose of comparison, a similar soil specimen was prepared and also consolidated to the confining pressure of $500 \mathrm{kPa}$, but to a looser state with the void ratio of $0 \cdot 761$. The results are superposed in Fig. 12. It is clear that this specimen in triaxial loading liquefied completely, with almost zero residual strength. Note that for this specimen drastic fluctuations in stress occurred throughout the shearing process, meaning that a stable microstructure could not be established.

\section{REFERENCES}

Bobei, D. (2004). Static liquefaction of sand with a small amount of fines. PhD thesis, University of New South Wales at Australian Defence Force Academy, Canberra, Australia.

Chu, J. (1999). Quasi-steady state: A real behaviour? Discussion/ reply. Can. Geotech. J. 36, No. 1, 190-191.

Cubrinovski, M. \& Ishihara, K. (1998). State of concept and modified elastoplaticity for sand modelling. Soils Found. 38, No. 4, 213-225.

Li, X. S. \& Dafalias, Y. F. (2000). Dilatancy for cohesionless soils. Géotechnique 50, No. 4, 449-460, http://dx.doi.org/10.1680/ geot.2000.50.4.449.

Lo, S. R., Rahman, M. M. \& Bobei, D. C. (2008). Limited flow behaviour of sand with fines under monotonic and cyclic loading. Proc. 2nd Int. Conf. on Geotechnical Engineering for Disaster Mitigation and Rehabilitation (GEDMAR08) 201-209, 
http://dx.doi.org/10.1007/978-3-540-79846-0. Beijing, PRC: Science Press Beijing and Springer.

Lo, S. R., Rahman, M. M. \& Bobei, D. C. (2010). Limited flow behaviour of sand with fines under monotonic and cyclic loading. Geomech. Geoengng 5, No. 1, 15-25, http://dx.doi.org/ $10.1080 / 17486020903452709$.

NRC (National Research Council) (1985). Liquefaction of soils during earthquakes. Washington, D.C., USA: National Academy Press.

Vaid, Y. P., Chung, E. K. F. \& Kuerbis, R. (1989). Preshearing and undrained response of sand. Soils Found. 29, No. 4, 49-61.

Vaid, Y. P., Eliadorani, A., Sivathayalan, S. et al. (1999). Quasisteady state: A real behaviour? Discussion/reply. Can. Geotech. J. 36, No. 1, 182-183.
Yang, J. \& Dai, B. B. (2011a). Is the quasi-steady state a real behaviour? A micromechanical perspective. Géotechnique 61, No. 2, 175-183, http://dx.doi.org/10.1680/geot.8.P.129.

Yang, J. \& Dai, B. B. (2011b). DEM analysis of soil fabric effects on behaviour of sand: Discussion. Géotechnique 61, No. 8, 715-719, http://dx.doi.org/10.1680/geot.2011.61.8.715.

Yang, J. \& Wei, L. M. (2011). Collapse of loose sand with addition of fines. Department of Civil Engineering, The University of Hong Kong, Working Paper.

Yoshimine, M. (1999). Quasi-steady state: A real behaviour?: Discussion/reply. Can. Geotech. J. 36, No. 1, 186-187.

Zhang, H. \& Garga, V. K. (1997). Quasi-steady state: a real behaviour? Can. Geotech. J. 34, No. 5, 749. 